\title{
Rancang Bangun Pendukung Keputusan Pemberian Kredit Pada Konsumen PT. Mashill Finance Dengan Menggunakan Metode AHP
}

\author{
Meiliawati ${ }^{1}$ \\ ${ }^{I}$ Program Studi Informasi, Fakultas Teknologi Informasi- Universitas Serang Raya \\ Jl. Raya Cilegon - Serang Km.5 Taman Drangong Kota serang - Banten, indonesia \\ ${ }^{1}$ Lhiyameidyahoo.co.id
}

\begin{abstract}
PT. Mashill Finance merupakan perusahaan yang bergerak dibidang pembiayaan segala merk otomotif terutama sepeda motor. PT. Mashill Finance memiliki kesulitan dalam memilih calon konsumen atau kreditur agar tidak terjadi kesalahan dalam memberikan kredit sepeda motor. Penelitian ini bertujuan untuk memudahkan pimpinan dalam memberikan keputusan pemilihan calon konsumen atau kreditur yang baik, serta dapat membantu operasional perusahaan dalam mengolah data konsumen sehingga dapat mengefiensikan waktu serta kinerja karyawan.Penelitian ini menggunakan metode observasi, wawancar serta studi pustaka yang bertempat di PT. Mashill Finance. Sistem ini dirancang dengan menggunakan metode AHP (Analytical Hierarchy Process), agar dapat mempermudah dalam membangun sebuah sistem pendukung keputusan pemberian kredit sepeda motor kepada konsumen dengan baik serta menggunakan software PHP (Hypertext Preprocessor) dan dengan MySQL server untuk dapat membangun sebuah sistem yang dibutuhkan.Dari hasil penelitian ini maka dapat menghasilkan sebuah sistem pendukung keputusan untuk pemberian kredit pada konsumen dengan mengggunakan metode AHP (Analytical Hierarkhi Process) sehingga dapat membantu dalam pemilihan konsumen yang layak.
\end{abstract}

Kata kunci: Sistem Pendukung Keputusan, Pemberian Kredit, AHP

\section{LATAR BELAKANG}

PT. Mashill Finance merupakan perusahaan yang bergerak dibidang pembiayaan segala merk otomotif terutama sepeda motor. Seperti diketahui kendaraan bermotor saat ini bukan lagi merupakan barang mewah, tetapi menjadi kebutuhan masyarakat yang digunakan sebagai alat untuk beraktifitas. Hal ini telah terbukti dengan banyaknya pengguna kendaraan bermotor baik di daerah perkotaan ataupun pedesaan. Banyak masyarakat yang lebih memilih naik kendaraan pribadi dari pada kendaraan umum untuk berpindah dari satu tempat ke tempat yang lain, karena mungkin biaya yang dikeluarkan relatif lebih murah.

Untuk mendapatkan kendaraan bermotor, masyarakat telah ditawarkan dengan berbagai kemudahan dalam pembelian kendaraan bermotor. Salah satu contohnya adalah pembelian kendaraan bermotor dengan sistem kredit dan didalam sistem tersebut juga relatif ringan dengan uang muka yang bisa disesuaikan. PT. Mashill Finance memberikan kredit kepada setiap calon konsumen sepeda motor dengan kriteria yang sudah ditentukan perusahaan.
Permasalahan yang terjadi di PT. Mashill Finance yaitu sulitnya memilih calon konsumen yang tepat dan layak untuk bisa menjadi penerima kredit di PT. Mashill Finance karena banyaknya data pemohon kredit sepeda motor yang meningkat serta banyak pula persyaratan yang harus penuhi konsumen sehingga membuat perusahaan kesulitan untuk memilih calon konsumen yang tepat.

Guna membantu mempercepat dan mempermudah proses pengambilan keputusan, diperlukan suatu bentuk Sistem Pendukung Keputusan (Decision Support Sistem). Tujuannya adalah untuk membantu pimpinan dalam memilih berbagai alternatif keputusan yang merupakan hasil pengolahan informasi yang diperoleh dengan menggunakan metode Analytical Hierarchy Process (AHP)

\section{DASAR TEORI}

\section{A. Sistem Pendukung Keputusan}

Sistem pendukung keputusan atau Decision Support System (DSS) merupakan sistem informasi pada level manajemen dari suatu organisasi yang mengkombinasikan data dan model analisis canggih atau peralatan data analisis untuk mendukung pengambilan yang semi terstruktur dan tidak terstruktur. DSS dirancang untuk membantu pengambilan keputusan organisasional. DSS biasanya tersusun dari database, model grafis atau matematik yang digunakan untuk proses bisnis, dan antarmuka pengguna yang digunakan oleh pengguna untuk berkomunikasi dengan DSS (Al Fata, 2007 : 13).

\section{B. Kredit}

Dalam bahasa latin kredit disebut "credere" yang artinya percaya. Maksudnya si pemberi kredit percaya kepada si penerima kredit, bahwa kredit yang disalurkan pasti akan dikembalikan sesuai perjanjian. Sedangkan bagi si penerima kredit berarti menerima kepercayaan, sehingga mempunyai kewajiban untuk membayar kembali pinjaman tersebut sesuai dengan jangka waktu (Kasmir, 2002 : 101-104)

Didalam Undang-Undang Perperusahaan finance Nomor 10 tahun 1998, Pengertian Kredit adalah penyediaan uang atau tagihan yang dapat dipersamakan dengan itu, berdasarkan persetujuan atau kesepakatan pinjam meminjaman antara 
perusahaan finance dengan pihak lain yang mewajibkan pihak peminjam melunasi utangnya setelah jangka waktu tertentu dengan pemberian bunga.

Kredit terkandung unsur-unsur yang direkatkan menjadi satu. Sehingga jika kita bicara kredit maka termasuk membicarakan unsur-unsur yang terkandung di dalamnya.

Adapun unsur-unsur yang terkandung dalam pemberian suatu fasilitas kredit adalah sebagai berikut:

1. Kepercayaan

Kepercayaan merupakan suatu keyakinan bagi si pemberi kredit bahwa kredit yang diberikan (baik berupa uang, barang atau jasa) benar-benar diterima kembali di masa yang akan datang sesuai jangka waktu kredit.

2. Kesepakatan

Kesepakatan dituangkan dalam suatu perjanjian dimana masing-masing pihak menandatangani hak dan kewajibannya masing-masing sebelum kredit dikucurkan.

3. Jangka waktu

Setiap kredit yang diberikan memiliki jangka waktu tertentu, jangka waktu ini mencakup masa pengembalian kredit yang telah disepakati

4. Resiko

Akibat adanya tenggang waktu, maka pengembalian kredit akan memungkinkan suatu resiko tidak tertagihnya atau macet pemberian suatu kredit.

5. Balas jasa

Bagi perusahaan finance balas jasa merupakan keuntungan atau pendapatan atas pemberian suatu kredit.

\section{Konsumen}

Pengertian Konsumen adalah setiap orang pemakai barang dan atau jasa yang tersedia dalam masyarakat, baik bagi kepentingan diri sendiri, keluarga, orang lain, maupun makhluk hidup lain dan tidak untuk diperdagangkan.

Menurut pengertian Pasal 1 angka 2 UU PK, Pengertian Definisi Konsumen adalah setiap orang pemakai barang dan/atau jasa yang tersedia dalam masyarakat, baik bagi kepentingan diri sendiri, keluarga, orang lain, maupun makhluk hidup lain dan tidak untuk diperdagangkan."

Lebih lanjut, di ilmu ekonomi ada dua jenis konumen, yakni konsumen antara dan konsumen akhir. Konsumen antara adalah distributor, agen dan pengecer. Mereka membeli barang bukan untuk dipakai, melainkan untuk diperdagangkan Sedangkan pengguna barang adalah konsumen akhir.

Yang dimaksud di dalam UU PK sebagai konsumen adalah konsumen akhir. Karena konsumen akhir memperoleh barang dan/atau jasa bukan untuk dijual kembali, melainkan untuk digunakan, baik bagi kepentingan dirinya sendiri, keluarga, orang lain dan makhluk hidup lain.

Sedangkan dalam ilmu ekonomi ada 2 cara dalam memperoleh barang, yaitu:

Membeli. Bagi orang yang memperoleh suatu barang dengan cara membeli, tentu ia terlibat dengan suatu perjanjian dengan pelaku usaha, dan konsumen memperoleh perlindungan hukum melalui perjanjian tersebut.
Cara lain selain membeli, yakni hadiah, hibah dan warisan. Untuk cara yang kedua ini, konsumen tidak terlibat dalam suatu hubungan kontraktual dengan pelaku usaha. Sehingga konsumen tidak mendapatkan perlindungan hukum dari suatu perjanjian. Untuk itu diperlukan perlindungan dari negara dalam bentuk peraturan yang melindungi keberadaan konsumen, dalam hal ini UU PK. (http://definisipengertian.com/2012/pengertian-definisikonsumen-menurut-para-ahli/).

\section{ANALYTICAL HIERARCHY PROCESS (AHP)}

Metode AHP (Analitycal Hierarchy Process) merupakan metode yang dikembangkan oleh Thomas L. Saat sekitar tahun 1970, metode ini merupakan sebuah kerangka untuk pengambilan keputusan dengan efektif atas persoalan yang kompleks.

Ada 4 prinsip dasar yang digunakan untuk memecahkan persoalan AHP (Analityccal Hierarchy Process) ini, yaitu membuat hirarki, penilaian kriteria dan alternatif, menentukan prioritas, dan mengkur konsistensi (Kusrini, 2007).

Apabila suatu permasalahan pengambilan keputusan ingin diselesaikan dengan menggunakan metode AHP (Analitycal Hierarchy Process), permasalahan tersebut perlu dimodelkan dengan tiga hirarki umum, yakni tujuan, kriteria (termasuk sub-sub kriteria), dan alternatif. Konsep dasar dari AHP (Analitycal Hierarchy Process) sebenarnya terletak dari penggunaan pairwise comparison matrix (matrix perbandingan berpasangan) untuk dapat mengahasilkan bobot relatif antar kriteria maupun alternatif.

Suatu kriteria akan dibandingkan dengan kriteria lainnya dalam hal seberapa penting terhadap pencapaian tujuaannya. Untuk menentukan matrix perbandingan berpasangan dapat menggunakan nilai atau skala perbandingan yang biasa digunakan untuk mengukurnya yaitu dengan menggunakan skala 1 sampai 9. Skala pengukuran ini biasa dikenal dengan skala perbandingan Saaty. Nilai-nilai yang digunakan untuk pengukuran atau penilaian untuk menentukan matrix perbandingan berpasangan disajikan dalam tabel berikut :

\begin{tabular}{|l|l|}
\hline $\begin{array}{l}\text { Intensitas } \\
\text { Kepentingan }\end{array}$ & Keterangan \\
\hline 1 (equal) & Kedua elemen sama pentingnya \\
\hline 3 (slightly) & $\begin{array}{l}\text { Elemen yang satu sedikit lebih penting } \\
\text { daripada elemn yang lainnya }\end{array}$ \\
\hline 5 (strongly) & $\begin{array}{l}\text { Elemen yang satu lebih penting daripada } \\
\text { elemen lainnya }\end{array}$ \\
\hline $\begin{array}{l}7 \text { (very } \\
\text { strong) }\end{array}$ & $\begin{array}{l}\text { Satu elemen jelas lebih mutlak penting } \\
\text { daripada elemen lainnya }\end{array}$ \\
\hline 9 (extreme) & $\begin{array}{l}\text { Satu elemen mutlak penting dari pada } \\
\text { elemen lainnya }\end{array}$ \\
\hline $2,4,6,8$ & $\begin{array}{l}\text { Nilai-nilai antara dua nilai pertimbangan } \\
\text { yang berdekatan }\end{array}$ \\
\hline Kebalikan & $\begin{array}{l}\text { Jika aktivitas i mendapat satu angka } \\
\text { ibandingkan dengan aktivitas j, maka } \mathrm{j} \\
\text { memiliki nilai kebalikannya } \\
\text { dibandingkan dengan i }\end{array}$ \\
\hline
\end{tabular}




\section{ANALISIS DAN PERANCANGAN SISTEM}

\section{A. ANALISIS AHP}

1. Menentukan Prioritas Kriteria

A. Membuat matriks perbandingan berpasangan

Pada tahap ini dilakukan penilaian perbandingan berpasangan antara satu kriteria dengan kriteria lainnya. Tabel 3.13 Matriks Perbandingan Berpasangan

\begin{tabular}{|c|c|c|c|c|c|}
\hline & $\begin{array}{c}\text { Capacit } \\
y\end{array}$ & $\begin{array}{c}\text { Chara } \\
\text { cter }\end{array}$ & $\begin{array}{c}\text { Capita } \\
l\end{array}$ & $\begin{array}{c}\text { Condit } \\
\text { ion }\end{array}$ & $\begin{array}{c}\text { Collate } \\
\text { ral }\end{array}$ \\
\hline Capacity & 1 & 5 & 7 & 5 & 3 \\
\hline Character & 0,2 & 1 & 4 & 2 & 6 \\
\hline Capital & 0,14 & 0,25 & 1 & 5 & 5 \\
\hline Condition & 0,2 & 0,5 & 0,2 & 1 & 3 \\
\hline Collateral & 0,33 & 0,2 & 0,5 & 0,20 & 1 \\
\hline Jumlah & 1,87 & 6,92 & 12,4 & 13,33 & 18 \\
\hline
\end{tabular}

Angka 1 pada kolom Capacity baris Capacity menggambarkan tingkat kepentingan yang sama antara Capacity dengan Capacity, sedangkan angka 5 pada kolom Character baris Capacity menunjukan kualitas sedikit lebih penting dibandingkan Capacity. Angka 0,2 pada kolom capacity baris character merupakan hasil perhitungan $1 /$ nilai pada kolom character baris Capacity (2). Angka yang lainnya diperoleh dengan cara yang sama.

\section{A. Membuat matriks nilai kriteria}

Matriks ini diperoleh dengan rumus berikut :

Nilai baris kolom baru $=$ nilai baris-kolom lama / jumlah masing-masing kolom lama.

Tabel 3.14 Matriks Nilai Kriteria

\begin{tabular}{|l|l|l|l|l|l|l|l|}
\hline & $\begin{array}{l}\text { Capa } \\
\text { city }\end{array}$ & $\begin{array}{l}\text { Char } \\
\text { acter }\end{array}$ & $\begin{array}{l}\text { Capi } \\
\text { tal }\end{array}$ & $\begin{array}{l}\text { Cond } \\
\text { ition }\end{array}$ & $\begin{array}{l}\text { Collate } \\
\text { ral }\end{array}$ & Jumlah & $\begin{array}{l}\text { Prior } \\
\text { itas }\end{array}$ \\
\hline $\begin{array}{l}\text { Capa } \\
\text { city }\end{array}$ & 0,53 & 0,72 & 0,56 & 0.37 & 0,16 & 2.34 & 0,47 \\
\hline $\begin{array}{l}\text { Char } \\
\text { acter }\end{array}$ & 0,10 & 0,14 & 0,32 & 0,15 & 0,33 & 1,04 & 0,21 \\
\hline $\begin{array}{l}\text { Capit } \\
\text { al }\end{array}$ & 0,07 & 0,03 & 0,08 & 0,37 & 0,27 & 0,82 & 0,17 \\
\hline $\begin{array}{l}\text { Condi } \\
\text { tion }\end{array}$ & 0,10 & 0,07 & 0,01 & 0,07 & 0,16 & 0,41 & 0.09 \\
\hline $\begin{array}{l}\text { Colla } \\
\text { teral }\end{array}$ & 0,17 & 0,02 & 0,01 & 0,02 & 0.05 & 0,27 & 0,06 \\
\hline
\end{tabular}

Nilai 0,53 pada kolom Capacity baris Capacity diperoleh dari nilai kolom Capacity baris Capacity tabel 3.13 dibagi jumlah kolom Capacity tabel 3.13. Nilai kolom jumlah pada tabel 3.14 diperoleh dari penjumlahan pada tiap barisnya. Nilai pada kolom prioritas diperoleh dari nilai pada kolom jumlah dibagi dengan jumlah kriteria, dalam hal ini 5 (lima).

Menghitung Principle Eigen Value (max)

Tabel 3.15 Matriks Principle Eigen Value (max)

\begin{tabular}{|c|c|c|c|}
\hline & $\begin{array}{c}\text { Jumlah Matriks } \\
\text { Perbandingan } \\
\text { Berpasangan }\end{array}$ & Prioritas & Hasil \\
\hline Capacity & 1,87 & 0,47 & 0,87 \\
\hline Character & 6,92 & 0,21 & 1,45 \\
\hline Capital & 12,4 & 0,17 & 2,1 \\
\hline Condition & 13,33 & 0,09 & 1,19 \\
\hline Collateral & 18 & 0,06 & 1,08 \\
\hline & \multicolumn{2}{|c|}{ Jumlah } & 6,72 \\
\hline
\end{tabular}

Perhitungan nilai consistency Index dan consistency Ratio

A. Consistency Index

$$
\begin{aligned}
& \text { Jumlah max }=6,72 \\
& \mathrm{n}(\text { jumlah kriteria })=5 \\
& \mathrm{CI}=(\max -5) /(5-1)=48,52 / 4=0,43 \\
& \text { consistency } \\
& \mathrm{C} 1 \quad=0,43 \\
& \mathrm{IRC} \quad=1,12 \\
& \mathrm{CR} \quad=\mathrm{CI} / \mathrm{IRC}=0,43 / 1,12=0,38
\end{aligned}
$$

*nilai IRC didapat dari daftar indeks random konsistensi tabel 3.12.

Karena nilai $\mathrm{CR}<0,1$, maka rasio konsistensi dari perhitungan tersebut diterima.

Menentukan prioritas Alternatif

Perhitungan alternatif dilakukan terhadap alternatf dari semua kriteria. Dalam sistem ini terdapat 5 kriteria yang berarti akan ada 5 perhitungan prioritas alternatif. Langkah-langkah perhitungannya sama seperti pada tabeltabel yang tertera di atas.

Menghitung prioritas alternatif dari kriteria capacity

Membuat matriks perbandingan berpasangan

Tabel 3.16 Matriks Perbandingan Berpasangan Kriteria capacity

\begin{tabular}{|c|c|c|c|c|c|}
\hline & $\begin{array}{c}\text { Konsu } \\
\text { men A }\end{array}$ & $\begin{array}{c}\text { Konsu } \\
\text { men B }\end{array}$ & $\begin{array}{c}\text { Konsu } \\
\text { men C }\end{array}$ & $\begin{array}{c}\text { Konsu } \\
\text { men D }\end{array}$ & $\begin{array}{c}\text { Konsu } \\
\text { men E }\end{array}$ \\
\hline Konsumen A & 1 & 3 & 6 & 5 & 7 \\
\hline Konsumen B & 0,33 & 1 & 2 & 6 & 7 \\
\hline Konsumen C & 0,17 & 0,5 & 1 & 4 & 3 \\
\hline Konsumen D & 0,2 & 0,17 & 0,25 & 1 & 8 \\
\hline Konsumen E & 0,14 & 0,14 & 0,33 & 0,13 & 1 \\
\hline Jumlah & 1,84 & 4,81 & 12 & 16,13 & 26 \\
\hline
\end{tabular}


Tabel 3.17 Matriks Nilai Kriteria capacity

\begin{tabular}{|c|c|c|c|c|c|c|c|}
\hline & $\begin{array}{l}\text { Kons } \\
\text { ume } \\
\mathrm{n} \mathrm{A}\end{array}$ & $\begin{array}{c}\text { Kons } \\
\text { ume } \\
\text { n B }\end{array}$ & $\begin{array}{l}\text { Kons } \\
\text { ume } \\
\text { n C }\end{array}$ & $\begin{array}{l}\text { Konsu } \\
\text { men D }\end{array}$ & $\begin{array}{c}\text { Kons } \\
\text { ume } \\
\mathrm{nE}\end{array}$ & Jumlah & $\begin{array}{l}\text { Priori } \\
\text { tas }\end{array}$ \\
\hline $\begin{array}{l}\text { Konsu } \\
\text { men A }\end{array}$ & 0,55 & 0,58 & 0,5 & 0.39 & 0,89 & 1,84 & 0,47 \\
\hline $\begin{array}{l}\text { Konsu } \\
\text { men B }\end{array}$ & 0,25 & 0,8 & 0,8 & 0,36 & 0,09 & 4,81 & 0,25 \\
\hline $\begin{array}{l}\text { Konsu } \\
\text { men C }\end{array}$ & 0,24 & 0,07 & 0,57 & 0,89 & 0,45 & 9,58 & 0,13 \\
\hline $\begin{array}{l}\text { Konsu } \\
\text { men D }\end{array}$ & 0,23 & 0,05 & 0,66 & 0,78 & 0,56 & 16,13 & 0,11 \\
\hline $\begin{array}{l}\text { Konsu } \\
\text { men E }\end{array}$ & 0,14 & 0,6 & 0,01 & 0,02 & 0.78 & 26 & 0,04 \\
\hline
\end{tabular}

Tabel 3.18 Matriks Principle Eigen Value (max)

\begin{tabular}{|c|c|c|c|}
\hline $\begin{array}{c}\text { kriteria } \\
\text { capacity }\end{array}$ & $\begin{array}{c}\text { Jumlah Matriks } \\
\text { Perbandingan } \\
\text { Berpasangan }\end{array}$ & Prioritas & Hasil \\
\hline Konsumen A & 1,84 & 0,47 & 0,06 \\
\hline Konsumen B & 4,81 & 0,25 & 1,2 \\
\hline Konsumen C & 9,58 & 0,13 & 1,24 \\
\hline Konsumen D & 16,13 & 0,11 & 1,77 \\
\hline Konsumen E & 26 & 0,04 & 0,64 \\
\hline & \multicolumn{3}{|c|}{ Jumlah } \\
\hline
\end{tabular}

Perhitungan nilai consistency Index dan consistency Ratio Consistency Index

Jumlah $\max$

$$
=6,13
$$

$\mathrm{N}($ jumlah kriteria)

$\mathrm{CI}=(\max -5) /(5-1)$

$=5$

$=48,52 / 4=0,28$

\section{A. consistency Ratio}

$\mathrm{C} 1=0,43$

IRC $=1,12$

$\mathrm{CR} \quad=\mathrm{CI} / \mathrm{IRC}=0,43 / 1,12=0,38$

*nilai IRC didapat dari daftar indeks random konsistensi tabel 3.12 .

Karena nilai $\mathrm{CR}<0,1$, maka rasio konsistensi dari perhitungan tersebut diterima.

\section{HASIL DAN PEMBAHASAN}

1. Tampilan Menu Proses AHP

Tampilan ini untuk menentukan nilai-nilai yang digunakan untuk membandingkan kriteria dan alternatif secara berpasangan. Nilai-nilai yang diiinputkan sesuai dengan tabel skala perbandingan berpasangan.

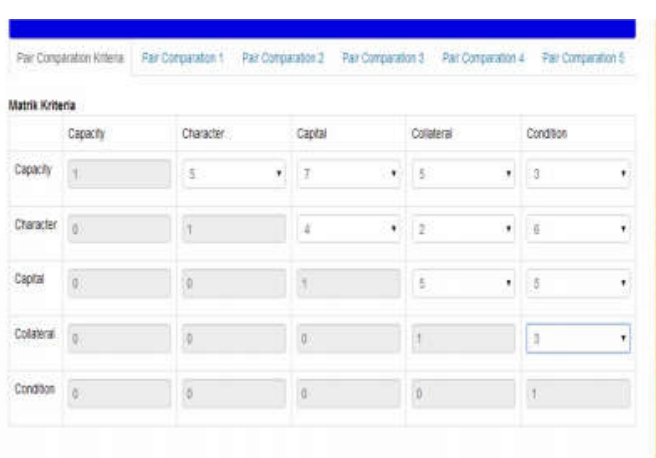

Tampilan menu proses AHP

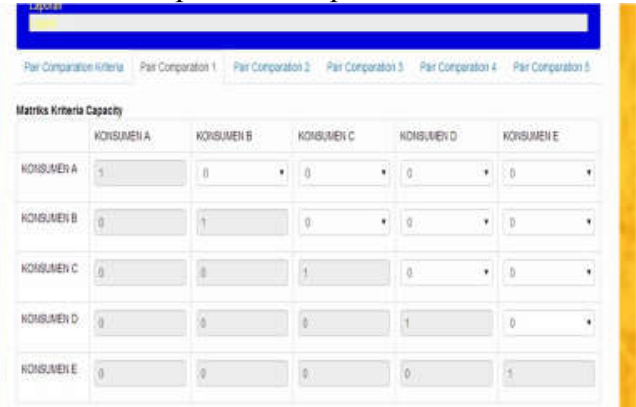

Tampilan menu proses AHP matrik alternatif

\section{DAFTAR PUSTAKA}

1. Taufiq, R. (2013). "Rancang Bangun Sistem Pendukung Keputusan Penilaian Kinerja Kependidikan Menggunakan Metode Analytical Hierarchi Process (Studi Kasus Di Fakultas Teknik Universitas Muhammadiyah Tangerang)." Jurnal Tekno Insentif Kopwil4. Vol. 7. No. (2). $36-44$.

2. Artika, R. (2013). "Penerapan Analitycal Hierarchy Proccces (AHP) Dalam Pendukung Keputusan Penilaian Kinerja Guru Pada SD Negeri 095224." Pelita Informatika Budi Darma. Vol. IV. No. (3). 1 - 6.

3. Kusrini Dan Gole, A W. (2007). "Sistem Pendukung Keputusan Penentuan Prestasi Pegawai Nakertrans Sumba Barat Di Waikabubak." SNATI 2007. ISSN: 1907-5022. Hal. D-47 s/d D-52.

4. Tominanto. (2012). "Sistem Pendukung Keputusan Dengan Metode Analytical Hierarchy Process (AHP) Untuk Penentuan Prestasi Kinerja Dokter Pada Rsud. Sukoharjo." INFOKES. Vol. 2. No. (1). 1 - 15. [7]

5. Indah, (2009), Sistem Informasi Geografis Fasilitas Kota Bogor Menggunakan Framework Pmapper, Institut Pertanian Bogor, Bogor pada tanggal 23 Juni 2014 pukul 13.14 WIB, diakses di http://repository.ipb.ac.id/ bitstream/handle/123456789/13023/G09ika.pdf?sequenc $\mathrm{e}=10$ 